of research misconduct that would embrace some forms of malfeasance beyond fabrication, falsification and plagiarism. His definition didn't cover bioethics, but it did class any breach of research regulations as misconduct.

Ryan's proposal was roundly condemned in the community, which fought a lengthy and successful battle to derail it. Researchers feared that the extension of misconduct investigations to embrace all kinds of professional laxity would lead to endless, fruitless investigation and, in particular, elicit groundless allegations from junior laboratory malcontents.

It is certainly true that there's a distinction between personal misbehaviour in the lab and outright scientific fraud, and it is perhaps as well that special investigative procedures are retained exclusively for the investigation of the latter. Furthermore, the question of what constitutes an ethical transgression may vary between societies that elect to impose different rules, whereas scientific fraud knows no borders.

In view of the pattern of behaviour that led up to Hwang's disgrace, however, no one should argue ever again that despotism, abuse of junior colleagues, promiscuous authorship on scientific papers or undisclosed payment of research subjects can be tolerated on the grounds of eccentricity or genius. Research ethics matter immensely to the health of the scientific enterprise. Anyone who thinks differently should seek employment in another sphere.

\section{Three cheers for peers}

\section{Thanks are due to researchers who act as referees, as editors resolve their often contradictory advice.}

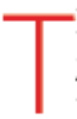

here is nothing like a high-profile fraud case to encourage journals to reflect on whether the standards and procedures they follow in selecting work for publication are thorough and appropriate. Misconduct creates a negative perception of journals' scientific peer-review processes, and the Hwang fraud saga has already fuelled some misconceptions about how the combination of referees and journal editors actually works.

Peer review remains by far the best available system for scientific quality control, however, and is an ultimately inspiring one at that. Nature is hugely grateful for the advice it receives from about 6,000 referees each year - typically two or three referees per paper. Most of their reports contain exactly what we need: a statement of what the referee considers the central message of the paper; an assessment of its significance; and a critique of technical or interpretational weaknesses, either in the work itself or in its presentation.

Between them, these elements add up to a verdict on the work's credibility and robustness. The system, it should be noted, is reliant on trust that what is written in the paper is actually true: it is not designed to detect the tiny minority of papers that are fraudulent.

The lives of editors and editorial boards of all journals are made interesting by the fact that, in many cases, the referees disagree on the verdict. And authors tend to be mightily upset if their papers are rejected when one or more reviewers are positive. Why, they demand to know, should the view of a negative reviewer be allowed to dominate the editors' selection decision?

To shed some light on how these decisions are reached, it is worth reflecting on some case studies of how and why referees differ in their view of papers submitted to Nature and the Nature research journals.

In one case, an exciting result relied on two techniques and a theoretical interpretation. The theoretical referee was very positive because the work validated an interesting idea. A specialist in one of the techniques was positive because he could find no flaw in its application. But the third referee uncovered a technical shortcoming in the second technique, and the paper was rejected after the editor assessed the significance of the shortcoming.

In another case, one of the referees recommended publication of a paper, but also pointed out limitations in the value of the finding. The editor concluded that the paper lacked the significance that would justify inclusion in the journal.

On many other occasions, however, the editors' discretion in making a decision results in a paper's publication. In one such case, referees criticized a molecular-biology paper for a lack of mechanistic insight and expressed reservations about the appropriateness of some of the techniques the authors used. But the editors felt that the therapeutic implications of the paper merited publication and, after resolving the technical issues raised by the referees, pushed ahead with publication of what turned out to be a highly cited development.

Another paper concerned the innovative application of chemistry to an environmental problem. But before publication, the editor orchestrated considerable iteration between referees from quite disparate backgrounds to ensure that a common understanding of the paper and its reliability had been established.

In another case, efforts to obtain review of a paper in genetics led to seven refusals to review, one damning review and only one positive review. In this case, the editor identified an experiment that would improve the paper and suggested it, yielding interesting results that were then published and well received.

Only in a minority of cases does every referee agree on whether or not to publish a paper. The above examples illustrate just a few ways in which such differences arise and demonstrate why journals would lose the respect of their authors and readers if they were to act robotically on the referees' advice. Moreover,

\section{"Only in a minority of cases does every referee agree on whether or not to publish a paper."} recommending, which can sometimes provide useful feedback to the selection process.

We would never claim that Nature's decision-making process is perfect. Its imperfections - along with those of every other journal - are among the multifarious reasons why over-reliance on journal publications as a measure of researchers' performance is dangerous. Nature has also dished out its fair share of historically embarrassing rejections (see Nature 425,$645 ; 2003$ ). We can only work to ensure that what we publish will do justice to the diversity of expertise that is brought to bear on its selection, and, above all, stand the test of time. 